\title{
ARQUEOLOGIA E PATRIMÔNIO: OS ACERVOS DOS MUSEUS E SUA IMPORTÂNCIA
}

A U T O R

Cláudio Umpierre Carlan
Pós-Doutorando em Arqueologia (NEPAM / UNICAMP); Professor Adjunto 2 de História Antiga da Universidade Federal de Alfenas; Membro do Grupo de Pesquisa Arqueologia Histórica da Unicamp.

\section{RES U M O}

O artigo começa com apresentação do museu, como um local, no qual abrigava os mais variados ramos das artes e ciências. Sofreu uma severa evolução desde os gabinetes de curiosidades dos séculos $\mathrm{XV}-\mathrm{XVI}$, até o século XXI, como o "guardião" da cultura material. Essa cultura material, diretamente associada ao Patrimônio Histórico, nos relata não apenas objetos produzidos pela inteligência humana, mas partes importantes do seu cotidiano.

Palavras-chave: Museu Patrimônio e Arqueologia

\section{A B S T R A C T}

the paper starts with presentation of the museum as place in which housed the various branches of the arts and sciences. he suffered a severe evolution from cabinet of curiosities the centuries XV - XVI, to XXI century as the "guardian" of material culture. This material culture, closely associated with the Historical Patrimony, tells us not only objects produced by human intelligence, but important parts of everyday life.

Key-words: Museum - Patrimony - Archeology

\section{N T R O D U Ç Ã O}

Historicamente o museu é responsável pela produção do conhecimento e a convergência dos saberes científicos. Não basta guardar o objeto. Sem uma pesquisa permanente, a instituição fica subestimada, a um centro de lazer e turismo. Cabe aos pesquisadores inserir os objetos, reclusos em suas reservas técnicas, como fontes históricas.

A pesquisa em si é uma visão crítica, a relação homem / objeto / espaço, formam a memória e o patrimônio cultural. Essa documentação museológica é um conjunto de informações sobre cada um dos seus itens e, conseqüentemente, a representação destes por meio de palavras ou imagens (CÂNDIDO: 2006, 37). Trata-se de um sistema de recuperação de informações, do passado, fundamental para a reconstrução cultural de uma sociedade.

A reserva técnica, como coração do museu, deve, ou pelo menos deveria, exercer um papel primordial dentro da instituição. Ela agrega uma grande leva de objetos, pertencente ao seu acervo, que por sua vez são marcas da memória. Para isso, devemos trazê-la para o campo do 
conhecimento histórico decodificando suas mensagens simbólicas. Uma série de informações intrínsecas e extrínsecas a serem identificadas.

A memória em si, ligada a aprendizagem, ou a uma função e experiência aprendida no passado, faz parte de uma preocupação básica com a sociedade. As exigências da vida em grupo resultam freqüentemente na modelagem da memória através da repressão, do enfoque em certas esferas de interesse. Não é uma propriedade da inteligência, mas a base, seja ele qual for, sobre a qual se inscrevem as concatenações dos atos.

Quanto a isto podemos destacar a memória social, na qual designa o caráter social da construção da memória humana: a associação com as questões do tempo e da história, como um meio de identificar e formar as identidades. Assim, nosso objetivo é o de realizar uma análise tanto da memória social ou coletiva, no sentido da identidade dos grupos, classes, tradição histórica, como também da memória individual, na realização de um fato social. Existindo desta forma uma relação entre memória e o documento.

Estes acervos, transformados em documentos, guardiões de uma memória coletiva, devem ser guardados e protegidos, mas não excluídos dos debates acadêmicos.

Os danos ao patrimônio estão regulamentados por leis de proteção. Na Espanha, por exemplo, as multas por danos vão de 60 a 600 mil euros. Além de prisão, sem direito a fiança. No Egito o contrabando de acervo arqueológico é tão grave quanto o tráfico de drogas.

Em 2006, foi publicado pelo IPHAN, Instituto do Patrimônio Histórico e Artístico Nacional, o livro Coletânea de Leis sobre Preservação do Patrimônio, resenhada por Pedro Paulo Funari, com objetivo de tornar público as leis que protegem os nossos bens históricos. A obra chega em uma boa hora, principalmente depois do episódio (mal explicado pela imprensa brasileira) da Marina da Glória, Rio de Janeiro, por ocasião dos Jogos Pan Americano.

Os organizadores dos jogos, os patrocinadores e o próprio Governo Municipal queriam realizar uma série de "reformas", descaracterizando totalmente um bem tombado. Na mesma linha, o roubo de peças do Museu de Arte de São Paulo (MASP) demonstra a importância não apenas da legislação patrimonial, como de práticas de gestão que incluam a sociedade civil. Como mostra a experiência internacional, e as recomendações da própria UNESCO, apenas políticas públicas que contemplem a participação de todos garante não apenas a conservação, como a vivificação da memória. Órgãos como o IPHAN e os conselhos estaduais e municipais de patrimônio só podem obter resultados duradouros e efetivos se incluírem a participação dos segmentos sociais.

Os museus, o patrimônio, como instituições públicas, não podem ficar com as portas fechadas para a população. Devem guardar seus acervos, não escondê-lo. Os objetos arqueológicos encarcerados nas reservas técnicas devem ser analisados, estudados e apresentados ao público, acadêmico ou não. Assim, a cultura material prosseguirá no seu caminho, de construção, ou melhor, de reconstrução do nosso passado histórico. 


\section{COLECIONISMO, ARQUEOLOGIAE PATRIMÔNIO H I S T Ó R I C O}

Hoje visto apenas como um hobby, o colecionismo sempre foi à primeira expressão de uma hierarquia política, econômica e social. Suetônio (69 140), no século I da Era Cristã, já relatava a importante coleção numismática do Imperador Augusto (63 a. C. -14 d.C.) ${ }^{1}$.

\begin{abstract}
${ }^{1} \mathrm{O}$ autor também descreve que apenas as pessoas do círculo pessoal do imperador tinham acesso à coleção. Alguns, como Marco Agripa (? - 12 a. C.), vencedor da Batalha do Actium contra Antônio e Cleópatra, amigo de infância do imperador, ajudou Augusto a montar essa coleção.
\end{abstract}

\footnotetext{
${ }^{2}$ O Museu Histórico Nacional / RJ, tem dois exemplares dessas moedas de ouro de Chindasvinto. A museológa Rejane Vieira publicou na Revista do Clube da Medalha (Casa da Moeda) um artigo sobre essas peças. Em 2005 apresentei no Programa de Estudos Medievais da UFRJ um trabalho sobre as cunhagens visigodas, tendo esses exemplares como modelo.
}

\footnotetext{
3 Era chamado de Porfirogêneto, nascido da púrpura em grego, por ter nascido no salão púrpura do palácio imperial de Constantinopla.
}

\footnotetext{
${ }^{4}$ Luís XIV (1638 - 1715) herdou a coleção do Cardeal Mazzarino (1602 1661) e, conseqüentemente a coleção de manuscritos de Carlos V (1338 1380), parte do acervo particular de Mazzarino.
}

Com a divisão da Europa, após a grande derrocada do Império Romano do Ocidente (476), os novos reinos germânicos, vulgarmente conhecidos por "reinos bárbaros", procuraram a legitimação dos seus governos no passado romano. Na Península Ibérica, o rei visigodo Chindasvinto (562 - 653), associou seu filho e sucessor Recesvinto (? - 672) ao trono, ainda em vida. Algo raro entre os jovens reinos germânicos. Como elemento legitimador do seu poder, Chindasvinto manda cunhar uma moeda de ouro, onde estão representados, no seu anverso, os bustos dele e do filho. O rei "bárbaro" usou o mesmo método de propaganda adotado pelos imperadores romanos: a moeda. Assim, conseguiu apaziguar o inconstante reino visigodo².

Durante o Renascimento Carolíngio, século VIII, Carlos Magno (747 - 814) estabeleceu leis, onde tudo que lembrasse a cultura romana fosse guardado. Preservar, recolher, recuperar, essa era a ordem do dia. Com isso, através de uma importante atividade cultural, o imperador franco é reconhecido pela Igreja como legítimo sucessor de Roma. Fato esse de vital importância para atual União Européia. O papa João Paulo II em seus discursos, fez uma alusão a importância de Carlos Magno, e seu avô Carlos Martel (688 - 741), para a Europa Cristã. A própria constituição européia referencia o governo dos francos. Notamos a influência do passado, legitimando o presente e o futuro.

No Império Romano do Oriente, Império Bizantino, também era comum durante festas religiosas, militares e políticas, exposições das coleções reais. O imperador Constantino VII Porfirogêneto (905 - 959), no século $X$, realizava anualmente essas exposições ${ }^{3}$.

Francesco Petrarca (1304 - 1374), célebre humanista e poeta italiano, considerado um dos precursores da coleção monetária na península itálica. Seu principal objetivo era conhecer a História de cada civilização através da moeda. Dono de um importante acervo, Petrarca defendia esses objetos arqueológicos como uma verdadeira paixão, porém, iniciou alguns métodos próprios, mais tarde adaptados pela metodologia científica.

A partir do Renascimento Artístico italiano, mais precisamente no século $X V$, tudo que lembrava Roma, a cidade modelo precisa ser imitada, começa a fazer parte das salas dos mecenas. As mesmo tempo que os pintores mesclam ideologia e mensagem política em seus quadros, as esculturas, mosaicos, moedas, objetos arqueológicos de uma maneira geral, também estão presentes. Essa revolução do olhar, acompanhada pela Expansão Marítima, leva as realezas européias dos séculos XVI e XVII a adquirirem suas próprias coleções ${ }^{4}$. O modelo da Vila Albani, em Roma, onde os intelectuais europeus se encontravam para discutir suas idéias e achados (entre eles o alemão Johann Winckelmann, 1719 - 1768, um dos fundadores da arqueologia científica). A vila pertencia ao cardeal Albani, sobrinho do Papa Clemente XI (1649 - 1721), grande protetor das artes, ordenou as primeiras escavações arqueológicas nas catacumbas romanas. A construção 
${ }^{5}$ Doutrinas das Moedas Antigas.

\footnotetext{
${ }^{6}$ Cidade Amuralhada de Carcassonne, Patrimônio da Humanidade pela Unesco desde 1997, possui o conjunto de muralhas mais antigo da França (século IV d.C.). É um dos pontos turísticos mais visitados do país, localizado próximo aos Pirineus Orientais, palco da Heresia dos Cátaros, no século XIII. Graças ao estudo dos objetos arqueológicos encontrados no sítio, foi possível datar sua ocupação por volta do ano 3000 a.C. Seu nome remonta a lenda da Dama de Carcas, princesa sarracena responsável pela defesa da cidadela, depois da morte do marido. Carlos Magno sitiou a cidade por mais de cinco anos sem sucesso. Quando exército franco iniciou a retirada, Carcas ordenou que tocassem todos os sinos. Carlos Magno teria exclamando Carcas Sonne. Na realidade, bem menos romântica, a cidade foi construída no topo do monte Carcasso.
}

da vila levou aproximadamente 20 anos. Nela, havia uma rica coleção grecoromana, hoje pertencente ao Museu do Louvre.

Ainda no século XVIII, o abade Joseph Eckhel (1737 - 1798), diretor do Gabinete Numismático de Viena e professor de Antigüidade, elabora os primeiros padrões científicos para a catalogação de moedas e medalhas. Tendo com base a coleção do Cardeal Médici, em Florença (Ekchel trabalhou muitos anos com essa coleção), estabelece a organização das peças cronologicamente (por países, reis, governos) em seu livro De Doctrina Nummarum Veterum ${ }^{5}$, escrita em oito volumes. Até hoje, referência nos museus quanto a organização dos acervos numismáticos (CARLAN: 2007, 26).

De uma maneira geral, as primeiras expedições arqueológicas tem início no século XVIII.. A palavra expedição está ligada às expedições militares que ocorreram tanto no século XVIII, quanto no século XIX. Essas campanhas eram acompanhadas por estudiosos e arqueólogos amadores. O principal exemplo desse momento, a descoberta da Pedra de Roseta, próximo a Alexandria pelas tropas napoleônicas em 1799. Sabendo da importância desse artefato, os ingleses incluíram no tratado de capitulação de 1801. Antes disso, em 1753, foi criado o Museu Britânico.

Com a Revolução Francesa, a partir de 1792, o Comitê de Salvação Pública (Terror), institui os primeiros decretos e aparatos jurídicos para proteção do Patrimônio Histórico Francês. Os bens da Igreja, realeza e nobreza passam a pertencer ao Estado. Os revolucionários tentam acabar com uma ideologia imposta pela elite, proprietária desses objetos. Em 1793 Louvre é transformado em museu, com o objetivo de instruir a Nação, difundir o civismo e a história. Os cidadãos teriam conhecimento do passado e, ao mesmo tempo, ocorria uma legitimação ideológica dos Estados Nacionais.

No Brasil, o Museu Real (hoje Museu Nacional, antigo palácio de D. Pedro II), foi criado por D. João VI em 1818. O próprio regente doou a primeira coleção de História Natural. O referente museu, durante os primeiros anos da República, foi palco das discussões racistas, consideradas na época científicas e modernas, defendidas pelo médico e antropólogo Raimundo Nina Rodrigues (1862 - 1906) que, por sua fez, foi influenciado pelo médico italiano Cesare Lombrosco (1835 - 1909).

Durante o século XIX, para muitos intelectuais o século das ciências, os primeiros conceitos de patrimônio e restauração são lançados. O arquiteto, arqueólogo e escritor francês Eugéne Viollet -le- Duc (1814 1879), pertencente a escola revivalista, precursor da moderna arquitetura, definiu as primeiras teorias das restauração e preservação patrimonial. $\mathrm{Na}$ realidade, Viollet - le - Duc, influenciado pelo romantismo, baseou grande parte do seu trabalho no imaginário medieval, valorizando o Gótico. Seus estudos realizados em Carcassonne, histórica cidade do sul da França, foram considerados pioneiros ${ }^{6}$. 


\section{USEU HISTÓRICO NACIONALEO ACERVO \\ N U M I S M Á T I C O}

O conjunto arquitetônico que hoje abriga o Museu, teve origem a partir do Forte de Santiago, na Ponta do Calabouço, um dos pontos estratégicos para a defesa da cidade do Rio de Janeiro, construído entre os séculos XVI e XVII, para defesa da região, prevendo uma futura invasão de corsários franc

Atualmente o MHN ocupa todo o espaço destinado a antiga ponta do Calabouço, local no qual se encontrava instalado originalmente o Forte de Santiago, construído em 1603, ao qual se acrescentou a Prisão do Calabouço (1693) - destinada a escravos faltosos - a Casa do Trem (1762) - depósito do "trem de artilharia", responsável pelo deslocamento interno de armas e munições, o Arsenal de Guerra (1764) e o Quartel do Exército (1835).

A instituição foi criada pelo decreto número 15596, de 02 de agosto de 1922 pelo então presidente da República, Epitácio Pessoa (1919-1922), com a função de museu voltado para a História do Brasil. Iniciou as suas atividades no dia 11 de outubro daquele mesmo ano, integrado à Exposição Internacional Comemorativa do Centenário da Independência do Brasil, instalado em duas galerias, nas dependências do antigo Arsenal de Guerra, (transferido para a ponta do Caju em 1908), ampliadas e decoradas para servirem como "Palácio das Grandes Indústrias", um dos pavilhões mais visitados da exposição.

A política de aquisição trazia para o museu insígnias militares, religiosas e nobiliárquicas, que, reunidas, retratavam a glória do passado, a nobreza do povo brasileiro, as forças emergentes da nação. Vargas, durante o Estado Novo (1937-1945), foi um dos grandes incentivadores, doando vários objetos pessoais para coleção. Assim sendo, foram entregues ao público, bens culturais até então dispersos, em outros órgãos institucionais, ou pouco valorizados (CHAGAS, GODOY: 1995, 39). Podemos citar como exemplo a coleção de numismática, que se encontrava na Biblioteca Nacional, desde o final do século XIX.

A origem da coleção é um tanto obscura. O corpo técnico do museu acredita que a maior parte das peças foi legado, em 1921, da grande coleção reunida pelo comendador Antonio Pedro de Andrade à Biblioteca Nacional, onde o seu antigo diretor, Ramiz Galvão, desde 1880 havia começado a formar o que mais tarde viria a ser a "coleção oficial brasileira".

Antonio Pedro reuniu uma coleção de 13.941 moedas e medalhas que compreende, entre outros núcleos expressivos, 4.559 moedas e 2.054 medalhas portuguesas e 4.420 moedas da Antigüidade.

É também possível que alguns exemplares sejam precedentes das coleções da família imperial, legadas pelo imperador D. Pedro II ao Museu Nacional em 1891 e incorporadas pela Biblioteca Nacional em 1896.

Em um relatório de 1881, dirigido ao Barão Homem de Melo, ministro de Império, que doou 114 moedas e 10 medalhas, Galvão utilizou diferentes argumentos para alcançar seus objetivos:

"A Biblioteca Nacional do Rio de Janeiro, exmo sñr., não possuía moedas nem medalhas por um vício de organização que é fácil de explicar; 
quando criada, pensou-se que esses trabalhos eram antes objetos de curiosidades, e por isso os deixaram fazendo parte do Museu Nacional...É todavia incontestável que moedas e medalhas são antes de tudo documentos subsidiários da história, e que por conseqüência o seu lugar próprio não é ao lado das coleções de história natural...o lugar da numismática é ao lado da história, e o da história é na Biblioteca Nacional. Pensando assim todas as grandes bibliotecas da Europa tem a sua seção de numismática..." (VIEIRA:1995, 98).

Segundo Poliano, é bem possível que Gustavo Barroso, primeiro diretor do MHN, tenha usado uma argumentação semelhante para conseguir a transferência da coleção da Biblioteca Nacional para o Museu Histórico (POLIANO: 1946, p.p. 9-10). O primeiro lote de peças, estava composto por 406 moedas e 6 medalhas e foi doado à biblioteca em setembro de 1880 . Nos anos seguintes, o acervo continuou a crescer, por meio de compras, ou doações, como, por exemplo, a doação da coleção do comendador Antonio Pedro de Andrade, que compreendia 13.941 moedas e medalhas, entre outros núcleos expressivos; de 4.559 moedas e 2.054 medalhas portuguesas; e de 4.420 moedas da Antigüidade.

Em 1922, quando o Museu Histórico Nacional foi criado, o decreto que $\mathrm{o}$ instituiu também determinou que o acervo numismático existente na Biblioteca Nacional - assim como em outras instituições como - Arquivo Nacional e a Casa da Moeda - fosse para ali transferido. No momento em que se efetivou a cessão, a coleção total ultrapassava as 48 mil peças.

Durante esse processo de transferência, foram lacradas uma grande quantidade de medalhas e moedas romanas, acompanhadas dos recibos de compras do século XIX. Toda essa documentação ficou "esquecida" na reserva técnica como refugo (lixo). Em 2002 começamos a analisá-la e identificamos, além de exemplares inéditos do Imperador Diocleciano, os detalhes citados pelos ourives portugueses, citadas nesses recibos, para indicar a raridade de uma determinada peça. Modelo esse utilizado durante a segunda metade do século XIX e início do século XX.

Grande parte dessa coleção é composta por moedas de bronze, naturalmente mais gastas, devido à sua maior circulação nas camadas mais populares do Império, que as de prata ou de ouro. E, artisticamente falando, de categoria inferior, estão determinadas por fatores históricos precisos e definidos; o seu estudo pode vir a elucidar traços fundamentais do momento histórico em que essas peças se difundem.

\section{CONSIDERAÇÕ ES F INA IS}

Em novembro de 2002, ano que o MHN comemorava seus 80 anos, foi inaugurada a exposição permanente "A História Através da Moeda", localizada na antiga Casa do Trem. Essa exposição, cronologicamente organizada, expõe algumas moedas da coleção, mostrando a riqueza do acervo. Inicia-se com as primeiras cunhagens, na Lídia segundo o historiador grego Heródoto, até o atual euro. Ao final, encontramos uma reprodução de um gabinete numismático do século XIX.

A numismática durante muito tempo ficou confinada às reservas 
técnicas dos museus, não sendo o objeto central de estudos ou análises. Ficando apenas cotejada ou, simplesmente, como um suporte para a documentação escrita. Hoje, no Brasil, existem uma série de estudos e análise tendo a moeda como objeto principal de análise.

O Museu oferece a outras instituições - museus, centros culturais, colégios e empresas - exposições itinerantes baseadas em seu acervo. As exposições disponíveis são: "O Império e a República", "A República no Traço de Rian", "Memória Cearense", "Imagens do Brasil", "Pelas Ruas e Calçadas - Comércio Informal e Ambulante Ontem e Hoje" e "Oreretama, A Terra do Índio".

Vale a pena uma passagem rápida pelo site do Museu Histórico Nacional www.museuhistoriconacioanl.com.br. Apesar de ainda estar sendo organizado, existe uma série de imagens sobre a estrutura do MHN, desde o século XVI até os dias atuais.

De gabinetes de curiosidades, arrumados de qualquer maneira, os museus sofreram uma profunda transformação a partir do século XVIII. Carl Von Linné (1707 - 1778), mais conhecido como Lineu, escreveu em 1768 seu livro Systema Naturae, onde institui a moderna organização da taxonomia (ciência da classificação), descrevendo o que chamou de nomenclatura binomial. Os Museus de História Natural, primeiramente, adotaram esse sistema. Mais tarde o método é adaptado para os outros objetos pertencentes as reservas técnicas.

A idéia de Patrimônio Histórico e Cultural, também sofreu uma série de influências a partir do século XX. De construções seculares e milenares, ampliam sua área de atuação para o Patrimônio Imaterial, como o Drama de Elche, na Espanha (1980) ou Samba de Roda do Recôncavo Baiano (Bahia) e o Samba Carioca do Rio de Janeiro, em 2008.

Analisando e estudando a cultura material, identificamos as técnicas, os usos e as diversas funções de cada objeto. Associados aos valores estéticos, históricos, simbólicos de uma época. É fundamental manter, preservar e estudar cada um desses objetos culturais. Função essa que, tanto o Departamento de Museus, quanto o IPHAN, tem por obrigação proteger para as gerações futuras.

\section{A G R A D E C I M E N T OS}

Aos amigos e colegas do NEPAM / Unicamp, em especial a Aline Carvalho e Pedro Paulo Funari, pela oportunidades de trocarmos ideias: a Vera Lúcia Tostes, Eliane Ney, Rejane Vieira.

A responsabilidade pelas ideias restringem-se ao autor. 
COLETÂNEA DE LEIS SOBRE PRESERVAÇÃO DO PATRIMÔNIO. Rio de Janeiro: IPHAN, 2006, 320 p.

CÂNDIDO, Maria Inez. Documentação Museológica. In: Caderno de Diretrizes Museológicas. Brasília/ MINC/IPHAN/Departamento de Museus e Centros Culturais. Belo Horizonte: Secretaria de Estado da Cultura/Superintendência de Museus, 2006, pp.34- 79.

CARVALHO, Margarida Maria de. LOPES, Maria Aparecida. FRANÇA, Susani Silveira Lemos (org.) As Cidades no Tempo. Franca: UNESP / Olho d'Água, 2005, 323 p.

CHAGAS, Mário. Museália. Rio de Janeiro: J C Editora, 1996, 186 p.

CHAGAS, Mario de Souza. GODOY, Solange de Sampaio. Tradição e Ruptura no Museu Histórico Nacional. In: Anais do Museu Histórico Nacional, volume 27, Rio de Janeiro: Museu Histórico Nacional, 1995, 158 p.

COSTA, Lygia Martins. De Museologia Arte e Políticas de Patrimônio. Rio de Janeiro: IPHAN, 2002, 388 p.

FUNARI, Pedro Paulo Abreu. Arqueologia e Patrimônio. Erechim: Habilis, 2007, 168 p.

FUNARI, Pedro Paulo Abreu e PELEGRINI, Sandra C. A. Patrimônio Histórico e Cultural. Rio de Janeiro: Jorge Zahar ed, 2006, 77 p.

HOBSBAWN, E.J. Nações e Nacionalismo desde 1780: programa, mito e realidade. Rio de Janeiro: Paz e Terra, 1990, $270 \mathrm{p}$.

POLIANO, Luis Marques. A Numismática no Museu Histórico Nacional. In: Revista Numismática. Números 1-4. São Paulo: Sociedade Numismática Brasileira, 1946.

SUETÔNIO. Vida de los doce césares. Obra completa, Madrid: Editorial Gredos, 1991.

VIEIRA, Rejane Maria Lobo. Uma grande coleção de moedas no Museu Histórico Nacional ? In: Anais do Museu Histórico Nacional, volume 27, Rio de Janeiro: Museu Histórico Nacional, 1995. 